\title{
Estimating Optimal Inflation Rate in Saudi Arabia: Using Dynamic Threshold Regression Model
}

\author{
Soleman O. Alsabban ${ }^{1} \&$ Sarah N. Alnuwaiser ${ }^{1}$ \\ ${ }^{1}$ Economic Research Department, Saudi Central Bank, Riyadh, Saudi Arabia \\ Correspondence: Soleman Alsabban, Economic Research Department, Saudi Central Bank, Riyadh, Saudi Arabia. \\ E-mail: Salsabban@sama.gov.sa
}

Received: January 14, 2021

Accepted: February 8, 2021

Online Published: February 15, 2021

doi:10.5539/ijef.v13n3p40

URL: https://doi.org/10.5539/ijef.v13n3p40

\begin{abstract}
This study evaluates the relationship between inflation and the output gap in Saudi Arabia. Specifically, it determines a level of optimal inflation for the output gap given the changes in the economic cycle. The novelty of this study's research question is linking optimal inflation with the non-oil output gap in Saudi Arabia by constructing a dynamic threshold regression model. The estimation is carried out by using a yearly time series from 1981 to 2019. The variables used in our model are based on existing economic theories that have established a correlation between the GDP gap as the dependent variable and inflation, money supply, and total exports as explanatory variables. The results obtained in this study suggest the existence of a threshold level of inflation of which the turning point is located at 3 percent.
\end{abstract}

Keywords: optimal inflation rate, inflation, output gap, threshold regression model

\section{Introduction}

A number of practitioners and academics have focused on the optimal inflation rate and its relationship with economic growth in the past decade. Some even took it further and investigated inflation rate with the output gap. That being said, fundamentally, the inflation rate differs between countries depending primarily on macroeconomic policies and economic structure. Given the recent pressures on the inflation rate in Saudi Arabia, including VAT increase, energy price reform, and expat levy, it is important to study the inflation rate behavior and its relationship with the output gap. The optimal inflation rate is important in stimulating investments and aggregate demand; as a result, creating jobs, increasing private consumption, and supporting the private sector.

There are various types of inflationary pressure; the two main types are (1) demand-side (demand-pull) inflation and (2) supply-side (cost-push) inflation. Demand-side inflation is the increase in prices due to high demand for goods and services with supply shortage (or without an increase in supply), which could be caused by overspending, surpassing economic capacity. In contrast, supply-side inflation is caused by an increase in production cost (raw materials, labor, or even input tax), leading to a decrease in the supply of goods and services and a relative increase in prices (Machlup, 1960). Demand-side inflation mostly occurs when an economy is expanding, as the increase in prices will promote GDP growth and a positive output gap due to the excess demand. However, supply-side inflation will cause GDP growth to fall and the output gap to shrink (or become negative). There are other drivers of inflation, for example, seasonality and money supply. Active seasons, such as Islamic occasions and holidays, could affect inflation due to high demand. Moreover, if the money supply grows faster than GDP, inflation will also occur.

This study aims to determine the optimal inflation level in Saudi Arabia. The results will enable policymakers to demonstrate the effect of the inflation rate on investment and consumption. The lack of economic studies examining the impact of the inflation rate on the output gap in Saudi Arabia makes this study significant. This study is considered one of the first studies that measure the inflation rate's impact on the output gap in Saudi Arabia. The study will be organized as follows: the second section reviews the recent literature, the third Section presents the methodology applied; the fourth section presents the empirical results. Finally, the conclusion in the last section.

\subsection{Analyzing Inflation and Economic Growth in Saudi Arabia}

In a broad definition, the output gap is the difference between the actual output and the potential output. The 
output gap usually measures the use of resources in the country. A positive output gap means that the economy exceeds full capacity, usually caused by demand shock (Fisher et al., 1997). There is a relationship between the output gap and inflation rate, as the positive output gap means that there is a surplus in demand for goods, services, and labor. This is commonly associated with an increase in price levels. Besides, money supply, oil prices, and imported inflation are the other factors that could lead to inflationary pressure.

Table 1. Comparison of selected macroeconomic indicators (2010-2019)

\begin{tabular}{|c|c|c|c|c|c|c|c|}
\hline Year & $\begin{array}{c}\text { Inflation } \\
\text { Rate \% }\end{array}$ & $\begin{array}{l}\text { Output } \\
\text { Gap \% } \\
\end{array}$ & $\begin{array}{c}\text { Private Consumption } \\
\% \\
\end{array}$ & $\begin{array}{c}\text { Private Sector } \\
\text { GDP \% } \\
\end{array}$ & $\begin{array}{c}\text { Inflation in trade } \\
\text { partners*(China) } \%\end{array}$ & $\begin{array}{c}\text { Money Supply } \\
\text { (M3) \% } \\
\end{array}$ & $\begin{array}{c}\text { Oil Prices } \\
\text { (Brent) US\$ }\end{array}$ \\
\hline 2010 & 3.8 & 3.4 & 3.9 & 10.5 & 3.2 & 5.0 & 79.6 \\
\hline 2011 & 3.7 & 3.5 & 1.7 & 8.1 & 5.6 & 14.7 & 111.4 \\
\hline 2012 & 2.9 & 2.6 & 11.7 & 5.6 & 2.6 & 13.6 & 111.6 \\
\hline 2013 & 3.5 & 2.8 & 3.2 & 7.0 & 2.6 & 10.9 & 108.6 \\
\hline 2014 & 2.2 & 2.8 & 6.1 & 5.4 & 1.9 & 11.6 & 99.1 \\
\hline 2015 & 1.3 & 1.2 & 6.8 & 3.4 & 1.4 & 2.5 & 52.4 \\
\hline 2016 & 2.0 & -1.8 & 0.9 & 0.07 & 2.0 & 0.8 & 43.8 \\
\hline 2017 & -0.9 & -2.6 & 3.2 & 1.5 & 1.6 & 0.3 & 54.2 \\
\hline 2018 & 2.5 & -2.8 & 1.9 & 1.9 & 2.1 & 2.7 & 71.2 \\
\hline 2019 & -2.1 & -2.8 & 4.5 & 3.8 & 2.3 & 7.1 & 64.3 \\
\hline
\end{tabular}

Source: GaStat, SAMA, IMF, and Alrashidi et al. (2020), * as a proxy of imported inflation.

From the table above, we noticed that in 2012, the inflation rate's value was close to the output gap, as the economy exceeded full capacity due to the positive output gap. What we know about demand-pull inflation is that increased consumption may affect prices rather than the production of goods and services, at least in the short term (Machlup, 1960). In 2012, private consumption growth coincided with an increase in the private-sector GDP, oil prices, and liquidity. However, these high rates did not affect the inflation rate in 2012 due to the consistent growth of the output gap. In addition, there is no significant difference between the local and foreign inflation rate (China), which could lead to protect competitive advantage for some exports. The relationship between the inflation rate and economic growth is commonly analyzed. As indicated by (Ayyoub et al., 2011), several studies find that high inflation is harmful to economic growth. However, the question is how to define "high inflation"? Fischer (1993) developed a growth approach that suggests that a high inflation rate will hinder economic growth due to decreased investment and productivity. In addition, Fischer (1993) states that growth has a negative relationship with inflation. In other words, a high inflation rate is not essential for sustained economic growth. Besides, he concludes that a low inflation rate and small budget deficit could lead to sustainable economic growth.

To analyze the effect of inflation rate (2018 base year) on private sector growth (2010 base year), and to simplify the analysis, the period (1981-2019) is divided into two categories: (1) years where inflation rates were greater than 5 percent, and (2) years where inflation rates were less than zero (negative inflation). Starting with the first category, in 1995, the inflation rate was about 5.3 percent; this rate was confronted by a modest growth rate of 1.5 percent in private sector GDP. As for 2007 and 2008, inflation registered rates of about 5.0 percent and 6.1 percent, respectively. This rise was due to the increase in food prices and house rentals. During the same period, the private sector's growth rate, investment, and private consumption exceeded 9.5 percent. As for the second category, the impact on private sector growth varied. During the period (1984-1987), negative inflation rates (average -2.9 percent) were accompanied by a negative growth rate in the private sector, with an average of -4.2 percent. In contrast, the periods (1990-1992) and (1997-2001) recorded negative inflation rates (average -0.9 percent and -1.0 percent), which were accompanied by positive growth rates in the private sector, averaging 4.4 percent and 4.1 percent, respectively. In light of recent studies discussing inflation rate effect on economic growth, some of the empirical studies supported the negative effect of high inflation on economic productivity, such as Khan and Senhadji (2000), Ayyoub et al. (2011), and Aydin et al. (2016). Moreover, some of these studies have set a threshold level for an optimal inflation rate. However, there are still arguments about how to determine the optimal inflation rate.

\section{Literature Review}

In the exciting literature, several studies tried to find the optimal inflation rate for economic growth based on different estimation techniques. The main findings of these studies are as follows: one of the major studies that examines the existence of the threshold effects was presented by Khan and Senhadji (2001). The study covers 140 developing and industrial countries for the period (1960-1998). The results obtained from the estimated 
model suggest that threshold level is lower in industrial countries as compared with developing countries. This is a strong evidence of the negative relationship between inflation and growth for inflation above a threshold level. The threshold was found around 1-3 percent for industrial countries and 7-11 percent for developing countries. Also, Dang's study (2011), which is applied to 182 developing countries and 31 developed countries, agrees with Khan \& Senhadji. The study uses annual data during the period (1961-2009) and indicates that there will be a negative effect on economic growth if the inflation rate exceeds 10 percent in developing countries. On the other hand, there is no evidence that inflation affects economic growth in developed countries.

Loi (2012) testes the relationship between inflation and economic growth in the United States. The study applies threshold model during the period (1960-2011). The model uses GDP growth as a dependent variable, and investment growth, population, economic openness and money supply as independent variables. The study concludes that the threshold is between 0 and 1.5 percent quarterly, which means that inflation rate will have a negative effect on the US economic growth if it is exceeds 1.5 percent.

With regard to developing countries, some studies address the inflation threshold for each country. Mubarik (2005) estimates the threshold level and finds the causality direction between economic growth and inflation in Pakistan. The study uses annual data from 1973 to 2000 by applying a threshold model where the analysis was built based on four variables: economic growth, inflation, population, and total investment growth rates. The study finds a 9 percent threshold inflation level. In other words, inflation will affect economic growth if its level exceeds 9 percent. Moreover, the granger causality test finds a causality direction from inflation to economic growth. A recent study on Pakistan by Ayyoub et al. (2011) empirically testes the relationship between inflation and economic growth during the period (1972-2010) by using Ordinary Least Square (OLS). They find a negative and significant relationship between inflation and growth. The results suggest a threshold level of less than 7 percent to promote GDP growth. Adusei (2012) reaches the same previous conclusion when the method is applied to South Africa during the period (1965-2010).

Thanh (2015) empirically estimates inflation threshold effects on growth for ASEAN-5 countries during the period (1980-2010) by applying Panel Smooth Transition Regression. The empirical results show that inflation will have a significant and negative impact on economic growth if the threshold level exceeds 7.84 percent. Omay and Kan (2010) use the same methodology, which is applied to 6 industrial countries, including Canada, France, Italy, Japan, UK, and the US, by using a dataset for the period (1972-2005). The results indicate that there will be a negative effect on economic growth if the inflation threshold level exceeds 2.52 percent.

Some studies have investigated the effect of optimal inflation on economies that are in a transition period. Aydin et al. (2016) cover Turkey, Azerbaijan, Kazakhstan, Kyrgyzstan, Uzbekistan, and Turkmenistan during the period 1992-2013 by adapting Dynamic Panel Threshold Model. The empirical model includes real GDP growth as a dependent variable, and inflation rate, investment, population growth, initial income level, openness, and the change in terms of trade as independent variables. The empirical findings illustrate that inflation will have a negative effect on economic growth if the level exceeds 7.97 percent. Regarding oil-exporting countries, Bawa et al. (2012) examine the inflation threshold effect on economic growth in Nigeria during the period from 1981 to 2009 by using Threshold Regression Model. The results estimate a threshold level of 13 percent for Nigeria. Whereas inflation rate below this level has a lower negative effect on growth. Concerning the optimal inflation rate in Saudi Arabia, Alkhatani and Elhendy (2014) examine the relationship between inflation and real GDP in Saudi Arabia during the period (1980-2010) by using a threshold model. The empirical findings of the study indicate that there is a non-linear relationship between inflation and growth. Moreover, the study recommends that the inflation rate should not exceed 4 percent because of its negative effect on economic growth.

To sum up, there are some convincing arguments for and against the fact the rate of inflation has a positive impact on economic growth. However, the literature review covered a wide variety of such studies and one study Alkhatani and Elhendy (2014) conducted on Saudi Arabia. However, there is still some controversy surrounding Saudi Arabia's optimal inflation. This study will focus on the optimal inflation of Saudi Arabia regarding the output gap.

\section{Data}

The model in this study is estimated by using a yearly time series from 1981 to 2019 retrieved from the Saudi General Authority for Statistics (GaStat) database and The Saudi Central Bank (SAMA) yearly statistics. The variables used in our model are as follows: Non-oil GDP gap $(G G A P)$ as the dependent variable. Consumer Price Index $(C P I)$ as an explanatory variable. The model also includes exogenous variables (control variables), which are: total investment by using Gross Fixed Capital Formation as a proxy $(I N V)$, total exports - oil and non-oil $(E X P)$, total imports (IMP), and money supply (M3). This study contains enough degrees of freedom with 39 
observations. It is worth mentioning that the non-oil output gap calculation is obtained from Alrashidi et al. (2020). The data is then processed for multiple diagnostic tests to make sure it fits the model, which will be presented in chapter 5 .

\section{Model Specification (Threshold Regression Model)}

This study considers the threshold models from several studies, such as Khan and Senhadji (2000), Mubarik (2005), and Nasir and Nawaz (2010). In this section, the aim is to clarify the process of building an empirical model by considering various variables. The simplified form of the model is as follows:

$$
\Delta\left(G G A P_{t}\right)=\alpha_{0}+\beta_{1} \Delta\left(\pi_{t}\right)+\delta_{t}
$$

Where $\triangle G G A P_{t}$ represents the change in the non-oil output gap, $\pi_{t}$ is the inflation rate, and $\delta_{t}$ is the error term. To estimate the threshold level, we include another inflation variable in equation (1). Accordingly, the equation can be rewritten as:

$$
\Delta\left(G G A P_{t}\right)=\alpha_{0}+\beta_{1}\left(\pi_{t}\right)+\beta_{2} D_{i}\left(\pi_{t}-\pi^{*}\right)+\delta_{t}
$$

Where the notation $D_{i}$ represents the dummy variable and $\pi^{*}$ is the expected threshold inflation level, the value of which is chosen randomly for estimation purposes in ascending order to estimate the threshold model. On the other hand, the dummy variable can take the following values:

$$
D_{i}=\left\{\begin{array}{l}
1, \text { if } \pi_{t}>\pi^{*} \\
0, \text { if } \pi_{t} \leq \pi^{*}
\end{array} i=1 \ldots N ; t=1 \ldots T\right.
$$

The term $D i=1$ represents inflation above the threshold level, whereas $D i=0$ indicates otherwise. After putting the value of $D i=1$, equation (2) is written as:

$$
\Delta\left(G G A P_{t}\right)=\alpha_{0}+\beta_{1}\left(\pi_{t}\right)+\beta_{2}\left(\pi_{t}-\pi^{*}\right)+\delta_{t}
$$

Consequently, equation (4) indicates that the effects of inflation and threshold levels of inflation on non-oil output growth are represented by $\beta 1$ and $\beta 2$. The effect of inflation on non-oil output growth is given by $\beta 1$ if Saudi Arabia is faced with a rate less or equal to the threshold inflation level. On the other hand, $\beta 1+\beta 2$ represents the situation where Saudi Arabia experiences a higher inflation rate. Furthermore, equation (4) can be rewritten to include the control variables as follows:

$$
\Delta\left(G_{G A P_{t}}\right)=\alpha_{0}+\beta_{1}\left(\pi_{t}\right)+\beta_{2}\left(\pi_{t}-\pi^{*}\right)+\beta_{3} X_{t}+\delta_{t}
$$

Where $X_{t}$ represents the four control variables used in the model. For instance, investment growth is incorporated as one of the control variables. According to Salai-i-Martin (1997), investment plays a prominent role in speeding up the process of economic growth. Another control variable taken into account in this study is exports and imports. According to Faisal et al. (2017), exports have a positive long-run relationship with economic growth in Saudi Arabia due to their close proximity to oil exports. Moreover, we have added Money supply (M3) as a control variable since it has an indirect impact on economic growth. From the standpoint of economic theory, a higher money supply generally leads to lower interest rates followed by an increase in investments, which results in higher GDP (Nizhegorodtsev \& Goridko, 2015).

\section{Empirical Results}

\subsection{Descriptive Statistics}

This subsection aims to present a set of common descriptions and features of the sample size in order to get a better understanding of the data in a sensible way, as shown in Table 2. In addition, the unit root test is

\begin{tabular}{|c|c|c|c|c|c|}
\hline \multicolumn{6}{|c|}{ Observations: 38, Duration: 1981 to 2019} \\
\hline \multicolumn{2}{|c|}{ Consumer Price Index (CPI) } & \multicolumn{2}{|c|}{ GDP Gap (GGDP) } & \multicolumn{2}{|c|}{ Money Supply (M3) } \\
\hline Mean & 0.010501 & Mean & -0.01322 & Mean & 0.087167 \\
\hline Std. Dev. & 0.024186 & Std. Dev. & 0.031162 & Std. Dev. & 0.070483 \\
\hline Minimum & -0.037179 & Minimum & -0.06343 & Minimum & 0.003036 \\
\hline Maximum & 0.060837 & Maximum & 0.046157 & Maximum & 0.321263 \\
\hline \multicolumn{2}{|c|}{ Total Exports $($ EXP) } & \multicolumn{2}{|c|}{ Investments (INV) } & \multicolumn{2}{|c|}{ Total Imports (IMP) } \\
\hline Mean & 0.085915 & Mean & 0.053147 & Mean & 0.056290 \\
\hline Std. Dev. & 0.275778 & Std. Dev. & 0.128520 & Std. Dev. & 0.147301 \\
\hline Minimum & -0.826356 & Minimum & -0.209118 & Minimum & -0.279386 \\
\hline Maximum & 0.474638 & Maximum & 0.278789 & Maximum & 0.293367 \\
\hline
\end{tabular}
implemented, given its importance in indicating if a trending behavior in the mean occurs within the data. Table 3 indicates that two tests (Augmented Dicky Fuller - ADF and Phillips Perron - PP) are used in this study to determine if it suffers from a systematic trend.

Table 2. Descriptive statistics 
By looking at the general description of the data in Table 2, it is clear that there are enough degrees of freedom to fit the model as there are 38 yearly observations. Descriptive results show that the Consumer Price Index (CPI) growth rate is 1.1 percent on average across all sample sizes. The Private Sector Real GDP (GDPPS) growth rate averaged about 4.2 percent. The descriptive statistics also show an objectively high average rate of 8.7 percent for money supply, higher than that of the United States that averaged 6 percent during the same period. Total Exports (EXP) recorded an average growth rate of 8.7 percent, which is possibly due to Saudi Arabia's high oil exports. Finally, the Gross Fixed Capital Formation (INV) showed an average growth rate of 5.3 percent.

\subsection{Diagnostic tests}

\subsubsection{Unit Root Test}

This study uses quantitative assessments on the variables by conducting a stationarity as well as cointegration analysis, as shown in Table 3 and Table 4. The results show a good fit of the variables into the model. Ultimately, stationarity indicates that the statistical properties of the sample size do not change over time. As can be seen in Table 3, the Augmented Dickey Fuller (ADF) test is implemented to examine the unit root in the data. The results show that, at 5 percent confidence level, all variables are stationary by taking the first difference. This study also uses the Phillips Perron (PP) test to confirm that all variables are stationary. The test results show that all variables are stationary and do not have a unit root.

Table 3. Unit Root Tests

\begin{tabular}{lcccc}
\hline & \multicolumn{2}{c}{ Augmented Dickey Fuller (ADF) } & \multicolumn{2}{c}{ Phillips Perron (PP) } \\
\cline { 2 - 5 } & \multicolumn{2}{c}{ Level Data } & Level Data \\
\hline & Constant & Trend & Constant & Trend \\
EXI & -8.878190 & -8.727746 & -9.079132 & -8.930671 \\
IMP & -7.482589 & -7.456134 & -14.97545 & -16.65262 \\
$G G A P$ & -6.307420 & -6.210218 & -11.35477 & -10.06149 \\
$I N V$ & -5.641138 & -5.547281 & -6.202789 & -6.116896 \\
M3 & -7.676622 & -7.565290 & -8.210855 & -8.610637 \\
\hline
\end{tabular}

Note. The ADF $5 \%$ critical values for constant $=-2.943427$, and for trend $=-3.536601$. For the PP constant $=-2.943427$, and for trend $=$ -3.536601 .

\subsubsection{Long-Run Relationship Test (Johansen Co-Integration)}

Furthermore, this study investigates the long-run relationship among the variables. Typically, a Johansen co-integration test is used for such a purpose. The results of the co-integrating vectors shown in Table 4 confirm that there are four multiple long-run relationships among the equations. Generally, the results support traditional economic theories regarding the impact of such variables on inflation and economic growth. For instance, movements in money supply, total exports, imports, and investments tend to affect movements in inflation and perhaps also potential GDP (Nazer, 2016; Alhamidy, 2016; and Looney, 1990). Therefore, as this study intends to determine the optimal inflation rate in the case of the non-oil GDP gap, control variables are used in order to minimize the external effects on inflation and on growth, such as money supply, total exports, imports, and investments.

Table 4. Johansen and Juselius (1990) Co-integration tests

\begin{tabular}{|c|c|c|c|}
\hline Null Hypothesis & Alternative Hypothesis & Trace Statistics & $5 \%$ Critical Value \\
\hline \multicolumn{4}{|l|}{ Panel A: Trace Test } \\
\hline$r=0 *$ & $r=1$ & 146.0345 & 95.75366 \\
\hline$r \leq 1^{*}$ & $r=2$ & 97.42230 & 69.81889 \\
\hline$r \leq 2 *$ & $r=3$ & 62.39048 & 47.85613 \\
\hline$r \leq 3$ & $r=4$ & 32.59684 & 29.79707 \\
\hline$r \leq 4 *$ & $r=5$ & 14.04598 & 15.49471 \\
\hline$r \leq 5^{*}$ & $r=6$ & 4.829141 & 3.841466 \\
\hline \multicolumn{4}{|c|}{ Panel B: Maximum Eigenvalue Test } \\
\hline$r=0$ & $r=1$ & 48.61219 & 40.07757 \\
\hline$r \leq 1$ & $r=2$ & 35.03182 & 33.87687 \\
\hline$r \leq 2$ & $r=3$ & 29.79364 & 27.58434 \\
\hline$r \leq 3$ & $r=4$ & 18.55087 & 21.13162 \\
\hline$r \leq 4^{*}$ & $r=5$ & 9.216837 & 14.26460 \\
\hline$r \leq 5^{*}$ & $r=6$ & 4.829141 & 3.841466 \\
\hline
\end{tabular}

Note. $\mathrm{r}$ denotes the number of co-integration vectors. $*$ signifies a co-integrated relationship. 


\subsubsection{Stability Test and Robustness Check}

In addition, for model robustness and stability check, this paper uses CUSUM of squares test to examine the consistency of the parameters. Figure 1 below is the plots of the cumulative sum of squares together with the 5\% critical lines. The test finds parameter instability if the cumulative sum of squares goes outside the area between the two critical lines. Under the null hypothesis, values of the sequence outside an expected range suggest structural change in the model over time. According to CUSUM of squares test, the data is stable, and the coefficients are consistent, which indicates that the model is robust and stable. The test is implemented on six models, of which each model represents changes in threshold levels. More specifically, Model 1 includes dummy 1 , model 2 includes dummy $2 \ldots$ model 6 includes dummy 6.
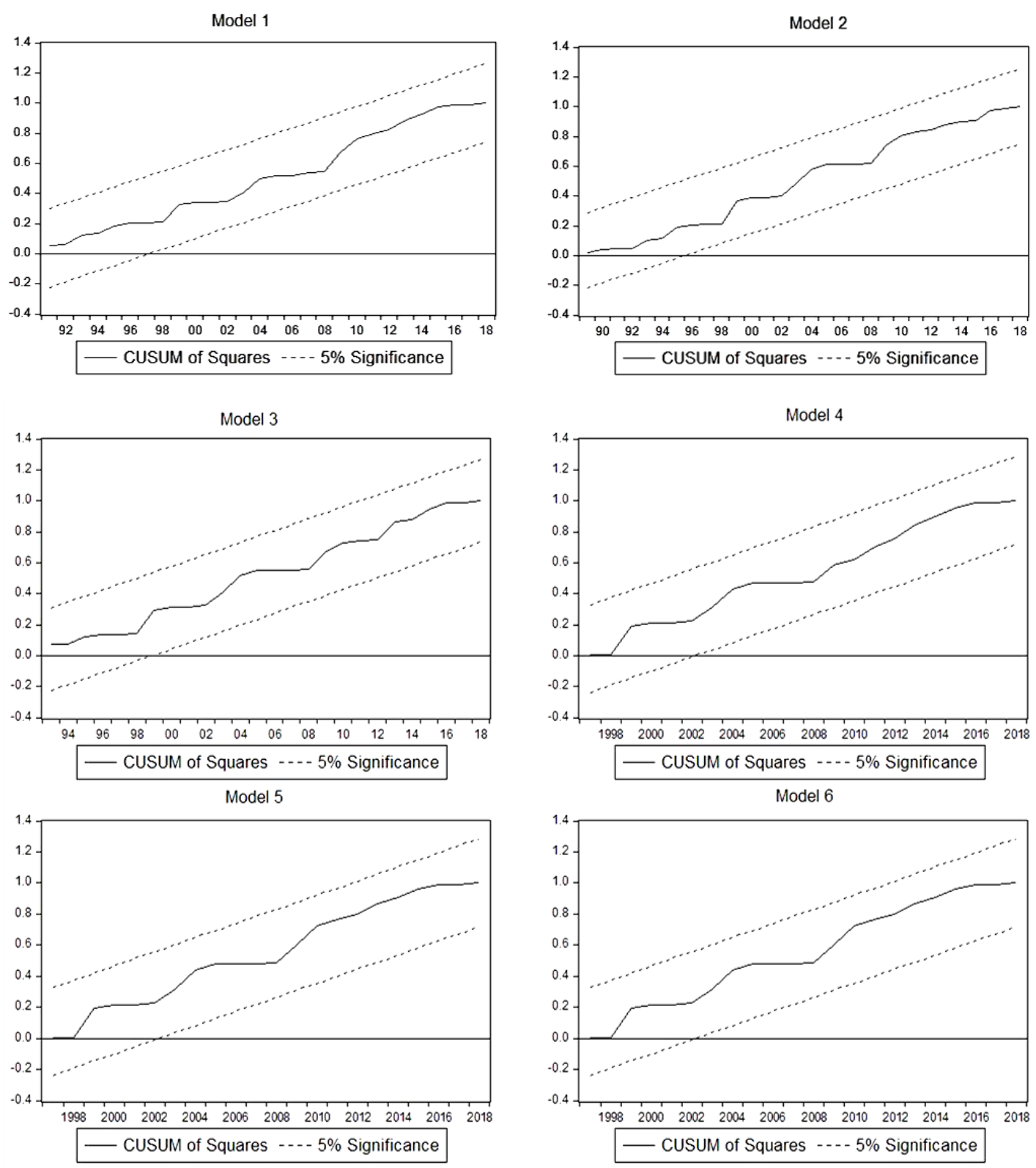

Figure 1. Model stability test (CUSUM of Squares Test)

\subsection{Threshold Regression Model Results}

Table 5 below shows the results of estimating the optimal threshold level of inflation for Saudi Arabia. By following previous studies such as Mosikari et al. (2018), Alkahtani and Elhendy (2014), and Sani and Ismaila (2012), the threshold level is determined at the minimum Sum of Squared Residuals (SSR). Accordingly, based 
on the threshold regression model, the lowest SSR is located at a 3 percent inflation for Saudi Arabia. At this level, if Saudi Arabia's inflation level is 3 percent, it would positively shock the non-oil output gap by an approximation of 0.5 percent. This would be beneficial in a period in which Saudi Arabia is operating above its potential GDP growth; therefore, everything else is constant, the 3 percent inflation level would result in improving the Saudi economy by closing the output gap. It is important to note that this study by no means implies that only a 3 percent level of inflation could affect the GDP gap in Saudi Arabia; however, it implies that by taking into account other economic factors, a 3 percent inflation level could have a positive impact on the Saudi economy. On the other hand, a 3 percent CPI level could close the output gap if the Saudi economy is operating below its potential level, where a 3 percent inflation will lead to widening the non-oil GDP gap. Ultimately, the impact of optimal inflation of 3 percent depends on the business cycle of Saudi Arabia, whether its operation above or below potential GDP. Specifically, a positive impact occurs when a 3 percent inflation overlaps with an above potential GDP performance in Saudi Arabia. Figure 2 shows a visual representation between the movements of the GDP gap and CPI from 1981 until 2019.

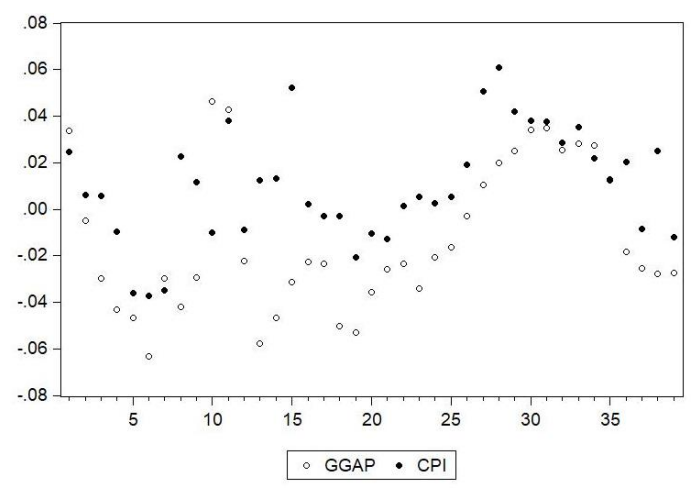

Figure 2. GDP Gap and CPI of Saudi Arabia (1981-2019)

Table 5. Estimation of Inflation Threshold Model at $\pi=1$ to $\pi=6$

\begin{tabular}{|c|c|c|c|c|c|c|c|}
\hline \multicolumn{8}{|c|}{ Dependent Variable: GGAP } \\
\hline$\pi$ & Variable & Coefficient & Std-error & t-stat. & probability & $\mathbf{R}^{2}$ & SSR \\
\hline \multirow{6}{*}{1} & CPI & 0.59014 & 0.162026 & 3.642247 & 0.001 & \multirow{6}{*}{0.560171} & \multirow{6}{*}{0.015158} \\
\hline & $\mathrm{D}_{1}(\mathrm{CPI})$ & -0.005334 & 0.01127 & -0.473265 & 0.6394 & & \\
\hline & EXP & -0.008513 & 0.018595 & -0.457815 & 0.6504 & & \\
\hline & IMP & 0.020202 & 0.045799 & 0.441098 & 0.6623 & & \\
\hline & INV & 0.075928 & 0.05748 & 1.320936 & 0.1965 & & \\
\hline & M3 & 0.079076 & 0.082193 & 0.962074 & 0.3437 & & \\
\hline \multirow{6}{*}{2} & CPI & 0.282476 & 0.271201 & 1.041573 & 0.3059 & \multirow{6}{*}{0.584682} & \multirow{6}{*}{0.015313} \\
\hline & $\mathrm{D}_{2}(\mathrm{CPI})$ & -0.009555 & 0.006743 & -1.416941 & 0.1668 & & \\
\hline & EXP & -0.007621 & 0.018018 & -0.422987 & 0.6753 & & \\
\hline & IMP & 0.003053 & 0.045905 & 0.066496 & 0.9474 & & \\
\hline & INV & 0.10155 & 0.058048 & 1.749424 & 0.0904 & & \\
\hline & M3 & 0.077947 & 0.078928 & 0.98757 & 0.3313 & & \\
\hline \multirow{6}{*}{3} & CPI & 0.416515 & 0.24949 & 1.669471 & 0.1054 & \multirow{6}{*}{0.569461} & \multirow{6}{*}{$0.01483 * *$} \\
\hline & $\mathrm{D}_{3}(\mathrm{CPI})$ & -0.004517 & 0.004825 & -0.935996 & 0.3567 & & \\
\hline & EXP & -0.012799 & 0.019092 & -0.670375 & 0.5077 & & \\
\hline & IMP & 0.012636 & 0.045815 & 0.275794 & 0.7846 & & \\
\hline & INV & 0.09629 & 0.059875 & 1.608188 & 0.1183 & & \\
\hline & M3 & 0.060478 & 0.081363 & 0.743309 & 0.4631 & & \\
\hline \multirow{6}{*}{4} & CPI & 0.588464 & 0.205717 & 2.860548 & 0.0076 & \multirow{6}{*}{0.556937} & \multirow{6}{*}{0.01527} \\
\hline & $\mathrm{D}_{4}(\mathrm{CPI})$ & -0.000226 & 0.003906 & -0.05792 & 0.9542 & & \\
\hline & EXP & -0.00809 & 0.019076 & -0.424116 & 0.6745 & & \\
\hline & IMP & 0.019577 & 0.046287 & 0.42294 & 0.6754 & & \\
\hline & INV & 0.078542 & 0.057787 & 1.359158 & 0.1842 & & \\
\hline & M3 & 0.07225 & 0.082138 & 0.879625 & 0.3861 & & \\
\hline
\end{tabular}




\begin{tabular}{|c|c|c|c|c|c|c|c|}
\hline \multirow{6}{*}{5} & CPI & 0.67922 & 0.197945 & 3.431359 & 0.0018 & \multirow{6}{*}{0.564469} & \multirow{6}{*}{0.01501} \\
\hline & $\mathrm{D}_{5}(\mathrm{CPI})$ & 0.002515 & 0.00348 & 0.722647 & 0.4755 & & \\
\hline & EXP & -0.00501 & 0.018863 & -0.26579 & 0.7922 & & \\
\hline & IMP & 0.015298 & 0.045856 & 0.333614 & 0.741 & & \\
\hline & INV & 0.069912 & 0.058142 & 1.202438 & 0.2386 & & \\
\hline & M3 & 0.089591 & 0.083993 & 1.066649 & 0.2946 & & \\
\hline \multirow{6}{*}{6} & $\mathrm{CPI}$ & 0.535884 & 0.172978 & 3.097996 & 0.0042 & \multirow{6}{*}{0.568816} & \multirow{6}{*}{0.01486} \\
\hline & $\mathrm{D}_{6}(\mathrm{CPI})$ & -0.00407 & 0.00447 & -0.91102 & 0.3695 & & \\
\hline & EXP & -0.0059 & 0.018482 & -0.31933 & 0.7517 & & \\
\hline & IMP & 0.030296 & 0.0469 & 0.645984 & 0.5232 & & \\
\hline & INV & 0.076413 & 0.056747 & 1.346543 & 0.1882 & & \\
\hline & M3 & 0.058532 & 0.081866 & 0.714973 & 0.4802 & & \\
\hline
\end{tabular}

$* * * \mathrm{p}<0.01, * * \mathrm{p}<0.05, * \mathrm{p}<0.1$

Figure 3 represents the relationship between inflation rate and the sum square of residuals (SSR), indicating that the lowest SSR of 0.01483 falls on a $3 \%$ CPI.

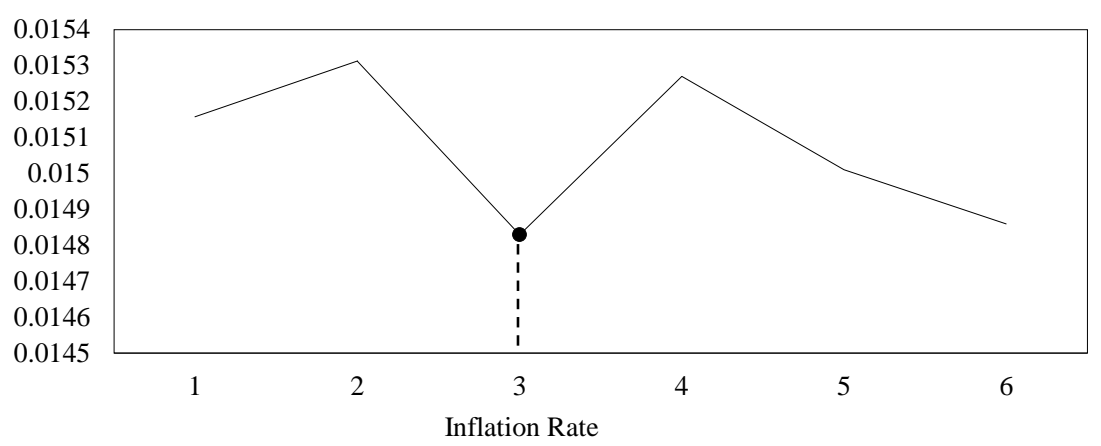

Figure 3. Sum of Squared Residuals (SSR) and inflation rate

Given the uniqueness and changes in economic structure between countries, changes in optimal inflation level is inevitable and expected when it is being compared between countries. The results of this study differ from Alkhatani and Elhendy (2014) where they have also investigated optimal inflation in Saudi Arabia. Their findings suggest that optimal inflation in Saudi Arabia is 4 percent. The variation in the results likely causes by few factors, such as differences in the dependent variable of which this study uses the non-oil GDP gap. In contrast, Alkhatani and Elhendy (2014) used overall GDP, also difference in the sample size and explanatory variables. For instance, according to Vinayagathasan (2013), optimal inflation is 5 percent in Asian countries, in Switzerland is found at 12 percent (Mosikari et al., 2018). Baharumshah, Slesman, and Wohar (2016) pointed out that the optimal inflation level is at 5 percent in emerging markets by using a panel data technique. In addition, Samir (2012) found that optimal inflation is approximately 10 percent in MENA (the Middle East and North Africa) region. Notably so, Samir's pointed out higher optimal inflation due to the presence of a very high inflation rates in some countries such as Turkey and Sudan, with an average of 15 percent across the sample size. Ultimately, as mentioned before, this study shed light on the optimal level of inflation given the state of the economy (GDP gap). In such a case where the economy is operating below its potential levels, maintaining a 3 percent inflation is optimal. It is essential to keep price levels stable in Saudi Arabia in order to fulfill its Vision 2030 of attracting more investments to ensure long-term economic sustainability.

\section{Conclusion}

The main objective of this study is to determine the optimal inflation rate for Saudi Arabia by using a threshold model. Given their relationship with inflation, we have controlled for money supply, total exports, imports, and investments in order to provide reliable outcomes. The results suggest the existence of a threshold level of inflation, the turning point of which is located at 3 percent. This level means that if Saudi Arabia's CPI level is 3 percent, it would positively shock the output gap by an approximation of 0.5 percent. In a situation where Saudi Arabia is operating above its potential GDP growth, a 3 percent CPI level would result in improving the Saudi economy by closing the gap. However, a 3 percent CPI level would close the gap if the economy were operating below its potential level. Generally, managing inflation through policies by using supply-side economy policies 
is often challenging and requires careful assessment. Inevitably, successful supply-side policies can contribute to economic growth without increasing inflation. In addition, stable and moderate levels of inflation encourages domestic and foreign investments through reducing uncertainties and increasing confidence. For future studies, it would be beneficial to use other control variables such as population growth, which also affects inflation in the long-run. In addition, it would be beneficial to use GDP components as dependent variables to obtain the optimal inflation rate.

\section{References}

Adusei, M. (2012). The inflation-growth nexus: Estimating the threshold effect for South Africa. Journal of Money, Investment and Banking, 26, 87-93. Retrieved from http://www.journalofmoneyinvestmentandbanking.com/

Al-Hamidy, A. (2011). Monetary policy in Saudi Arabia. BIS Papers, 57, 301-305. Retrieved from http://www.bis.org/

Alkahtani, S. H., \& Elhendy, M. A. (2014). Optimal inflation rate estimation for the Kingdom of Saudi Arabia: A threshold model approach. Life Science Journal, 11(4), 73-78. Retrieved from http://www.lifesciencesite.com/

Aydın, C., Esen, Ö., \& Bayrak, M. (2016). Inflation and economic growth: a dynamic panel threshold analysis for Turkish Republics in transition process. Procedia-Social and Behavioral Sciences, 229, 196-205. https://doi.org/10.1016/j.sbspro.2016.07.129

Ayyoub, M., Chaudhry, I. S., \& Farooq, F. (2011). Does Inflation Affect Economic Growth? The case of Pakistan. Pakistan Journal of Social Sciences (PJSS), 31(1).

Baharumshah, A. Z., Slesman, L., \& Wohar, M. E. (2016). Inflation, inflation uncertainty, and economic growth in emerging and developing countries: Panel data evidence. Economic Systems, 40(4), 638-657. https://doi.org/10.1016/j.ecosys.2016.02.009

Bawa, S., \& Abdullahi, I. S. (2012). Threshold effect of inflation on economic growth in Nigeria. CBN Journal of Applied Statistics, 3(1), 43-63. Retrieved from http://hdl.handle.net/10419/142057

Fischer, S. (1993). The role of macroeconomic factors in growth. Journal of Monetary Economics, 32(3), 485-512. https://doi.org/10.1016/0304-3932(93)90027-d

Fisher, P. G., Mahadeva, L., \& Whitley, J. D. (1997). The output gap and inflation- Experience at the Bank of England. BIS Conference Papers, 4, 68-90. Retrieved from http://www.bis.org/

Greenspan, A. (1977). Investment risk: the new dimension of policy. The Economist, 6.

Jha, R., \& Dang, T. N. (2012). Inflation variability and the relationship between inflation and growth. Macroeconomics and Finance in Emerging Market Economies, 5(1), 3-17. https://doi.org/10.1080/17520843.2011.608371

Khan, M. S., \& Abdelhak, S. S. (2001). Threshold effects in the relationship between inflation and growth. IMF Staff Papers, 48(1), 1-21. https://doi.org/10.5089/9781451853339.001

Loi, H. (2012). Inflation and growth: An estimate of the threshold level of inflation in the US. Retrieved from http://thekeep.eiu.edu/theses/808

Looney, R. E. (1990). Infrastructure investment and inflation in Saudi Arabia. International Journal of Transport Economics/Rivista internazionale di economia dei trasporti, 267-283. Retrieved from https://www.jstor.org/stable/42747123

Machlup, F. (1960). Another view of cost-push and demand-pull inflation. The Review of Economics and Statistics, 42(2), 125-139. https://doi.org/10.2307/1926532

Mubarik, Y. A. (2005). Inflation and growth: An estimate of the threshold level of inflation in Pakistan. Karachi: State Bank of Pakistan - Research Bulletin, 1(1), 35-44. Retrieved from https://www.sbp.org.pk/

Nazer, Y. (2016). Causes of inflation in Saudi Arabia. The Business \& Management Review, 7(3), 147.

Omay, T., \& Kan, E. Ö. (2010). Re-examining the threshold effects in the inflation-growth nexus with cross-sectionally dependent non-linear panel: Evidence from six industrialized economies. Economic Modelling, 27(5), 996-1005. https://doi.org/10.1016/j.econmod.2010.04.011

Thanh, S. D. (2015). Threshold effects of inflation on growth in the ASEAN-5 countries: A Panel Smooth Transition Regression approach. Journal of Economics, Finance and Administrative Science, 20(38), 41-48. 
https://doi.org/10.1016/j.jefas.2015.01.003

Vinayagathasan, T. (2013). Inflation and economic growth: A dynamic panel threshold analysis for Asian economies. Journal of Asian Economics, 26, 31-41. https://doi.org/10.1016/j.asieco.2013.04.001

\section{Copyrights}

Copyright for this article is retained by the author(s), with first publication rights granted to the journal.

This is an open-access article distributed under the terms and conditions of the Creative Commons Attribution license (http://creativecommons.org/licenses/by/4.0/). 